\title{
El sistema de continuidad: montaje y causalidad
}

\author{
Josep PróSPer Ribes \\ Universidad Politécnica de Valencia
}

\section{Resumen:}

El sistema de continuidad se basa en la causalidad y en un conjunto de reglas de montaje cuya función principal es la creación de un espacio-tiempo coherente que permita al espectador centrase en la historia propuesta por el universo diegético del relato.

Palabras claves: Continuidad audiovisual, montaje audiovisual, causalidad

\section{The continuity system: assembly and causation}

\begin{abstract}
:
The system of continuity is based on the causation and in a set of rules of assembly which principal function is the creation of a coherent space-time that allows the spectator focus attention on the history proposed by the universe diegético of the story.
\end{abstract}

Key Words: Audio-visual continuity, Audio-visual assembly, causation

\section{Referencia normalizada:}

Prósper Ribes, J. (2013) El sistema de continuidad: montaje y causalidad. Historia y Comunicación Social. Vol. 18 No Especial Octubre. Págs. 377-386.

Sumario: 1. Introducción. 2. Metodología. 3. Fundamentos del sistema de continuidad. 4. La unión entre planos: el racord. 5. La orientación espacial y la ley del eje. 6. Conclusiones 7. Referencias bibliográficas. 8. Notas.

\section{Introducción}

Los estudios sobre el sistema de continuidad audiovisual se han realizado principalmente desde un enfoque narrativo, histórico y desde la perspectiva del montaje. Por lo que respecta al planteamiento narrativo ha prevalecido el análisis de la causalidad y coherencia del relato, de la relación entre la historia y el discurso y de los modelos de representación narrativa. En el enfoque histórico se analiza la implantación de la continuidad en un momento concreto y la evolución histórica de su estilo y formas de producción. Por lo que respecta al montaje, los estudios tienen una doble vertiente: en primer lugar, análisis del conjunto de normas a seguir (vertiente normativa) y en segundo lugar examen del relato como resultado del proceso de montaje (vertiente teórico-práctica). Hay que tener en cuenta que estos tres enfoques no tienen que realizarse necesariamente por separado y en determinadas obras han ido estrechamente 
unidos, como es el caso de del trabajo de Bordwell, Staiger y Thompson (1997): El cine clásico de Hollywood. Sin embargo, la literatura específica sobre el montaje ha sido la más abundante y de una gran calidad. El hecho de considerar el montaje como uno de los componentes más específicos del relato audiovisual ha sido fundamental para que se produjera una gran cantidad de estudios. Pero hay que tener en cuenta, que la mayor parte de esos trabajos se han centrado sobre el modelo clásico, es decir, en el examen del conjunto de procedimientos que permiten que pase desapercibido al espectador el trabajo productivo.

\section{Metodología}

La metodología ha consistido, en primer lugar, en realizar un profundo análisis sobre el estado de la cuestión en la materia. Las diversas teorías nos han permitido llevar a cabo un panorama general sobre el concepto y su uso concreto en la narrativa audiovisual. En segundo lugar, hemos tomado como referencias el racord, como medio de conseguir fluidez en la transición entre planos, y la regla de los 180 grados o ley del eje como elementos consustanciales al sistema de continuidad. Estos elementos permiten configurar un espacio homogéneo, con similitudes con el real, aunque a cambio de introducir un conjunto de normas desde la planificación al montaje final. El aspecto más desarrollado en nuestro estudio del sistema de continuidad es el del montaje. Hay que tener en cuenta, que en el montaje hemos tenido en consideración las tres acepciones del término:

1.- El montaje como proceso puramente técnico que radica en unir físicamente una serie o conjunto de imágenes, independientemente del soporte. En este sentido, es una actividad básicamente mecánica que hace referencia al manejo de herramientas de montaje y edición.

2.- El montaje como un proceso donde se unen con precisión un conjunto de imágenes visuales y auditivas. En este sentido, el montaje consiste en ajustar adecuadamente los distintos planos y los sonidos para obtener un resultado concreto. En el sistema de continuidad el objetivo fundamental es la fluidez narrativa, que las transiciones no se noten y que la unión de los distintos planos establezca un espacio-tiempo coherente. Esta labor requiere el recurso a una serie de reglas que condicionan tanto el proceso de montaje como el de rodaje o grabación.

3.- El montaje como asociación de imágenes visuales y auditivas para dotarlas de sentido. A través de la relación de los distintos planos y los sonidos, se asigna unos significados a los acontecimientos, a veces más allá de su simple apariencia. Es una actividad fundamentalmente creativa.

El estudio del montaje es uno de los fundamentos para comprender cómo funciona el sistema de continuidad y es consecuencia de un concepto narrativo que pretende convertir al espectador que observa el universo diegético propuesto en un relato audiovisual en un ente ubicuo. 


\section{Fundamentos del sistema de continuidad}

Uno de los principios básicos en los que se sustenta el relato clásico audiovisual es la construcción de un espectador ubicuo que observa lo que ocurre en un espacio diegético desde distintos puntos de vista. El espacio único y coherente de la realidad es fragmentado para mostrarlo al espectador de forma que pueda percibir de la mejor manera posible los diversos acontecimientos que tienen lugar en la diégesis. Pero al fragmentar el espacio es necesario que el espectador pueda relacionar los distintos fragmentos (planos) entre sí y dotar al espacio de coherencia y lógica. En caso contrario, el espectador puede desorientarse en el espacio fragmentado del relato audiovisual. Por este motivo, existen toda una serie de procedimientos de grabación y montaje que han surgido a lo largo del tiempo y cuya finalidad es que el espectador siempre sepa en qué punto del espacio está observando un acontecimiento.

El discurso audiovisual es un proceso secuencial que muestra una historia donde una serie de personajes ejecutan y padecen acciones y acontecimientos. La sucesión discursiva plantea una relación entre la continuidad y la discontinuidad. Por una parte, el relato tiene continuidad ya que hay una historia pero por otra parte, esta historia es mostrada de forma fragmentada en el relato clásico audiovisual. Para solucionar este problema y dotar al relato de coherencia se recurre por una parte a la causalidad donde la lógica de los hechos implica que todo obedezca a una causa-efecto dentro del universo propuesto por la diégesis. Por otra parte, y al mismo tiempo, hay que proponer al espectador un espacio-tiempo narrativo y audiovisual coherente donde tengan lugar los acontecimientos que se desarrollan en la diégesis. En el sistema de continuidad la percepción de la historia por parte de los espectadores debe prevalecer sobre la percepción de los elementos discursivos. Se intenta justificar diegéticamente los elementos que puedan "alertar" al espectador de un trabajo productivo ajeno a la diégesis. Así, se tiende a que los movimientos y desplazamientos de cámara, por ejemplo, se justifiquen bien por otros movimientos o desplazamientos de personajes diegéticos, bien por necesidades dramáticas y siempre procurando que sean uniformes. De esta manera, surgen reglas destinadas a evitar que estos movimientos causen algún tipo de "molestia perceptiva" en el espectador y se evita, por ejemplo la transición por corte entre panorámicas. Uno de los mecanismos más significativos es la presencia de un narrador ya sea diegético ya sea extradiegético, pero siempre asimilado dentro del relato, que actúa como intermediario entre la historia y el espectador, en ocasiones también con la figura de un narratario generalmente diegético.

Ya en los primero tiempos, fueron apareciendo una serie de normas cuyo objetivo principal era "sumergir" al espectador en el universo diegético creado por el relato. Por ejemplo, en una época tan temprana como 1909, en Estados Unidos no se permitía a los actores mirar a cámara, tal y como ha señalado Burch (1987: 220 y ss.). El motivo es muy simple: en los relatos de ficción, si el actor mira a cámara parece que mire al espectador y, como consecuencia, se rompe el denominado efecto de la transparencia, es decir, el efecto es desvelar la ficción que se desarrolla al margen del espectador. Pero hay todavía algo mucho más curioso. Al mismo tiempo que surgían 
estas normas que estaban configurando el sistema de continuidad, iba apareciendo la parodia del propio sistema de continuidad. Para Thompson las parodias de la continuidad aparecen a partir de 1915 (Bordwell, Staiger y Thompson, 1997: 235 y 236). En algunos casos se llega a parodiar desde una mala fotografía a los problemas de continuidad en el vestuario, como que un personaje entre en una habitación con un traje y salga con otro o bien que otro personaje después de ensuciar un sombrero blanco, se lo vuelva a poner de un blanco inmaculado. Por lo tanto, al menos en una buena parte, el sistema de continuidad estaba arraigado en los procesos de producción ya que únicamente se puede parodiar lo que presenta una serie de reglas estables e identificables de las que poder burlarse. Cuando se parodia un género determinado es sencillamente porque hay esta serie de reglas que permiten identificar un género concreto. Los objetivos finales eran muy claros:

Las diversas normas de continuidad -planos de situación y resituación, insertos, dirección en la pantalla, continuidad de mirada, PCP, montaje paralelo- tenían dos objetivos básicos. Por una parte, permitían que la narración siguiera adelante en un espacio definido con claridad. Por otra parte, creaban una narración omnipresente que cambiaba con frecuencia la posición que el espectador tenía con respecto a la acción con objeto de que estuviera atento a las partes de la escena más importantes para la trama. ${ }^{1}$

Por lo tanto, la idea básica era que a través del uso de una serie de reglas el espectador no notara el proceso creativo y solamente permaneciera atento a la historia, es decir, la aparición de un modelo narrativo donde la historia solapa al discurso. Es el efecto de la transparencia. Siguiendo a Ortega y Gasset (1976: 20 y 21), podemos comparar la historia con un jardín y el discurso con el vidrio a través del que observamos dicho jardín. Si el vidrio es completamente transparente, nuestra visión se centrará en el jardín, sin fijarnos en el vidrio. Por el contrario, si es un vidrio con muchos adornos y poca transparencia, no permitirá observar con nitidez el jardín. Todo depende del objetivo final. Si se pretende que el espectador se centre en el jardín (la historia), cuanto más limpio y translúcido sea el vidrio (discurso), mucho mejor. Pero no todo es blanco o negro, sino que hay toda una gama de posibilidades intermedias, incluso que el vidrio esté sucio. En el efecto de la transparencia se debe conseguir que el espectador perciba el jardín sin que note, al menos excesivamente, el vidrio. Sin embargo, hay todo un complejo proceso técnico para lograr este efecto. Al respecto, Gómez Tarín (2011: 225) hace constar que la fragmentación implica una violencia sobre la percepción y que únicamente "gracias a la implantación de unos códigos y su paulatina asunción por los espectadores que esa violencia ha podido devenir en una suavidad casi imperceptible."

El montaje fragmentado que utiliza el sistema de continuidad está muy lejos de ser un procedimiento natural. Es más, algunos autores como Aumont (1997: 46) opinan que "El cine nació, y el dato está lejos de ser indiferente, como máquina de producir imágenes -vistas- continuas, no fragmentadas, largas." Ahora bien, el sistema de continuidad pretende que el espectador se desplace por el universo diegético y para lograrlo debe recurrir a la fragmentación, y es a través del montaje y de la causalidad como consigue que el espectador no note el procedimiento. En resumen, el montaje 
en continuidad representa una fractura con la unidad del espacio-tiempo real. Pero se ha convertido en el sistema dominante y ha conseguido prevalecer, aunque con cambios, a lo largo del tiempo. Pinel señala que:

La hermosa mecánica del montaje hollywoodiense de los años treinta y cuarenta se consideró durante largo tiempo como un triunfo casi definitivo. El montaje, íntimamente ligado a la planificación, era uno de los engranajes de una escritura lisa y transparente que, sin excluir ni la invención ni el vigor de la puesta en escena, imponía la discreción del modo de representación. Este montaje sirvió de modelo para todas las cinematografías del mundo (...) No obstante, algunos realizadores importantes (los que podemos calificar de autores) lo vulneraron gravemente. ${ }^{2}$

Es curiosa la opinión final de Pinel que califica de "autores" a los realizadores que no siguen el sistema de continuidad. Pero esta opinión también encierra una cierta verdad: el sistema se ha convertido en un procedimiento que implica la subordinación de cualquier otro sistema. Sin embargo, el modelo no tiene que mantener siempre los mismos procedimientos concretos, sino que tiene la capacidad de evolucionar a lo largo del tiempo mientras mantiene sus estructuras fundamentales.

\section{La unión entre planos: el racord}

Para conseguir el efecto adecuado de trasparencia discursiva, es imprescindible que la unión entre los planos sea fluida. Es tan importante en el montaje la unión de los diversos planos que componen el relato, que para Bordwell y Tompson (1993: 247) "Se puede considerar al montaje como la coordinación de un plano con el siguiente." Todo el estilo del relato está condicionado por las transiciones narrativas entre planos que es la manera en que el espacio-tiempo será mostrado al espectador. Llegados a este punto, es importante introducir el concepto de racord para entender adecuadamente el proceso de montaje en el sistema de continuidad. Bordwell y Tompson (1993: 261) señalan que: "La finalidad básica del sistema continuo es hacer que la transición de un plano a otro sea suave." Pero como ya hemos comentado, el montaje supone una ruptura y cada plano implica discontinuidad. En este sentido, Aumont señala:

El montaje, el cambio de plano, el cambio brusco en general en el cine, ha sido una de las mayores violencias cometidas nunca contra la percepción "natural". Nada en nuestro entorno modifica nunca todas sus características tan total y tan bruscamente como la imagen fílmica, y nada en los espectáculos preexistentes al cine los había preparado para semejante brutalidad. ${ }^{3}$

Sin embargo, a través de una serie de recursos de planificación, rodaje y montaje que el espectador ha acabado por aceptar, se ha conseguido que las transiciones entre planos apenas sean percibidas como tales por el espectador. Para Amiel (2005: 9) el montaje se fue imponiendo poco a poco utilizando complejos procedimientos técnicos. El montaje es, por lo tanto, el resultado de una evolución histórica. Y dentro de esta evolución está el racord. El concepto básico de racord hace referencia a una 
serie de procedimientos para ajustar dos imágenes que muestran planos distintos. El cambio de un plano a otro debe realizarse de manera fluida con el objetivo de permitir que el espectador perciba una continuidad y una lógica en la transición de una imagen a otra imagen y que la variación del punto de vista facilite su integración en el universo diegético. Una de las definiciones más exactas y citadas de racord pertenece a Karel Reisz:

Raccordar quiere decir unir dos planos de manera que el paso de uno a otro no dé lugar a una falta de coordinación entre ambos, que rompería la ilusión de estar viendo una acción continuada... Pero, como veremos después, todas las "reglas" de raccord están sujetas a la más amplia disciplina dramática, en contraposición a las exigencias mecánicas, hasta el punto de que nunca deben considerarse de validez universal. ${ }^{4}$

Esta es la idea básica: enlazar dos o más imágenes de manera que el cambio sea fluido, pero siempre subordinado a la causalidad que impera en la diégesis. Para Amiel (2005: 36) el corte no debe implicar "una ruptura radical y definitiva, sino como una costura que permite ensamblar trozos diferentes con la mayor discreción." El racord debe tener dos cualidades básicas:

1.- Ajuste adecuado de las imágenes de diversos planos para que den sensación de fluidez.

2.- Articulación entre diversos momentos narrativos cuando tiene lugar una transición narrativa entre planos consecutivos.

Normalmente, cuando se hace menciona el racord se toma como referencia la imagen visual, pero también es necesario hacer una referencia al racord sonoro. El sonido diegético más importante es, salvo excepciones, la palabra. Para Chion:

Formular que el sonido en el cine es vococentrista, es recordar que en casi todos los casos favorece a la voz, la pone en evidencia y la destaca de entre los demás sonidos. La voz es lo que recoge, en el rodaje, la toma de sonido, que es casi siempre, de hecho, una toma de voz; y la voz es lo que se aísla en la mezcla como instrumento solista del que los demás sonidos músicas o ruidos, no serían sino el acompañamiento. ${ }^{5}$

Lo importante es que se entienda la palabra, que sea inteligible, con la excepción de personajes que por necesidades dramáticas no se les deba entender. De hecho, en determinados relatos audiovisuales informativos cuando no se entiende correctamente a un personaje se le suele subtitular. Es también el caso de la película La vendedora de rosas: los personajes están interpretados por actores y actrices no profesionales que no vocalizan correctamente. Para que fueran adecuadamente entendidos, se subtitulo sus diálogos. Por lo tanto, el sonido está subordinado a la palabra. Además, entre planos diferentes se debe mantener el correcto nivel. El sonido también puede facilitar un cambio de plano que resulte visualmente deficiente, tal y como explica Reisz (1960: 202).

Los ajustes entre planos implican tanto una continuidad puramente mecánica como otra narrativa. Hay que recordar que la causalidad es uno de los principios básicos 
del relato clásico. Por eso es tan flexible el sistema. Puede fallar ocasionalmente en un relato concreto algún procedimiento técnico pero el sistema sigue vigente. Y, lo mejor, el espectador no suele notarlo. Hay multitud de ejemplos. Señalemos algunos. En la película Amelie tenemos un caso ejemplar cuando en el plano A (de referencia) Amelie de pequeña va a tomar una fotografía. Aprieta el botón de la cámara con la mano izquierda y en el plano B (de referencia) con la mano derecha. Realmente, esto no supone un error significativo, pero es un claro caso de desajuste entre planos. Lo mismo ocurre en otras películas de gran presupuesto y prestigio dentro del campo profesional como Titanic. Señalemos simplemente dos errores. El primero sucede durante la cena de Rose con su prometido Aquí se puede apreciar que Rose lleva un collar. Cuando instantes después sale a la cubierta del barco, el collar ha desaparecido. Otro caso ejemplar es el momento en que Rose intenta rescatar a Jack. Ve un hacha contra incendios y la coge, aunque para ello deba romper el cristal que la protege con una manguera. El siguiente plano nos muestra a Rose delante de la caja donde estaba el hacha y el cristal está intacto. Son errores de racord que están en la gran mayoría de las películas y sin embargo en muchos casos pasas desapercibidos. Esto es debido a que el espectador se encuentra completamente sumergido en la propuesta diegética que la plantea el relato y mientras esos errores no le despisten o provoquen desconcierto sobre lo que ocurre en la diégesis, el espectador los aceptará en el caso de que los perciba o, simplemente, no los apreciará.

El análisis de los distintos procedimientos para construir el racord permite establecer diversos modelos narrativos, ya que no todos los relatos tienen que ceñirse al precepto del racord siguiendo los planteamientos y normas que imperan en el sistema de continuidad. Ejemplos muy diferentes al modelo clásico los encontramos en modelos narrativos como el soviético con directores como Eisenstein que "fuerza" el racord para repetir acciones entre planos como forma de crear un efecto dramático (El acorazado Potemkin) o introduce insertos no diegéticos (Octubre).

\section{La orientación espacial y la ley del eje}

En la narrativa clásica audiovisual, el punto de vista que se ofrece al espectador sobre los acontecimientos que suceden en el universo diegético, se modifica constantemente. El espectador "viaja" a través del espacio diegético. En este sentido, es imprescindible que tenga una correcta referencia de donde están los personajes y, sobre todo, de donde está situado el propio espectador. Par lograrlo, se desarrolló una de las normas más controvertidas pero más respetadas por los profesionales: la regla de los 180 grados o ley del eje. Al respecto, Bordwell y Thompson señalan:

La regla de los $180^{\circ}$ se precia de delinear el espacio claramente. El espectador sabrá siempre dónde están los personajes en relación unos con otros y con el decorado. Y lo que es más importante, el espectador sabrá siempre dónde está él con respecto a la acción de la historia. El espacio de la escena, revelado de forma clara y nada ambigua, no debe sorprender o desorientar, porque esta desorientación, 
según se cree, apartaría al espectador del centro de la atención: la cadena de causas y efectos de la narración. ${ }^{6}$

Su función, por lo tanto, es situar correctamente al espectador ubicuo del relato clásico en relación al espacio diegético y al movimiento y desplazamiento de los personajes, de forma que siempre tenga una referencia espacial. Cuando los personajes y objetos se desplazan en el espacio o bien ocupan un lugar concreto, establecen una línea imaginaria (el eje) entre ellos y en relación a la colocación de la cámara. Steven Katz (2002: 129) señala que el eje "Se concibió originalmente para asegurarse de que al rodar una secuencia desde varias posiciones distintas de cámara, éstas pudieran montarse sin una confusa inversión de las mitades izquierda y derecha de la pantalla." El conjunto de normas que rigen la ley del eje fueron evolucionando a lo largo del tiempo hasta convertirse en uno de los procedimientos técnicos más asentados, tal y como señala Sánchez (1971: 110). La ley del eje permite modificar los puntos de vista y que el espectador tenga conciencia de su situación respecto al universo diegético.

Todos estos elementos crean un espacio único compuesto por el espacio en campo (lo que se muestra en un momento determinado) y el espacio fuera de campo (lo que se mostró anteriormente -espacio fuera de campo conocido- o lo que se sugiere a partir del espacio en campo-espacio fuera de campo supuesto-). Es el espacio narrativo el que concede sentido a la diégesis y aporta un lugar donde se desarrollan todos los acontecimientos. Obviamente, su construcción implica un trabajo productivo y también que los espectadores de manera gradual aceptaran un modelo de representación que es el dominante: el sistema de continuidad. El racord, como medio de conseguir fluidez en la transición entre planos, y la regla de los 189 grados para orientar al espectador en el espacio diegético, son elementos consustanciales al sistema de continuidad. Estos elementos permiten configurar un espacio homogéneo, con similitudes con el real, aunque a consta de introducir un conjunto de normas desde la planificación al montaje final.

Por supuesto, hay otros muchos procedimientos narrativos, tal y como ya hemos comentado. Una aproximación para considerar grandes bloque de modelos narrativos es, precisamente, la causalidad y el montaje en continuidad. Por ejemplo, Jenaro Talens considera que Un perro andaluz es una obra audiovisual donde se mantienen los principios básicos del racord pero no la causalidad. Para Talens (1989: 53) "La forma en que esta supuesta historia está narrada, impide un acercamiento de acuerdo con el modelo analítico clásico por su continua ruptura de la lógica de las acciones," En nuestra opinión, es este último aspecto es el que concede a la obra su carácter vanguardista.

\section{Conclusiones}

1. En el relato clásico audiovisual, los acontecimientos y personajes que los ejecutan y padecen son mostrados al espectador desde distintos puntos de vista. Este 
procedimiento implica que el espacio diegético es constantemente fragmentado, convirtiendo al espectador en un sujeto ubicuo que "percibe" el universo diegético desde distintos puntos de vista de manera sucesiva y a veces simultánea. Exactamente ocurre lo mismo con el factor temporal. Para estar correctamente emplazado en este espacio-tiempo diegético, es imprescindible un sistema que le oriente en todo momento, que lo situé correctamente con respecto a la acción y a los personajes.

2. El sistema de continuidad audiovisual es un procedimiento narrativo cuya función principal es crear un universo diegético coherente donde el espectador pueda identificarse con los personajes y sucesos al mismo tiempo que se encuentre siempre orientado espacial y temporalmente. El sistema de continuidad se fundamenta en la causalidad y en una serie de normas de montaje que crean un relato con un espacio y un tiempo coherentes para representar un universo diegético.

3. El montaje utilizado en el sistema de continuidad, es un procedimiento muy flexible, que es capaz de evolucionar con el tiempo. Resulta básico el ajuste correcto entre planos o racord para evitar que se "note" la técnica y la creación de un espacio audiovisual donde el respeto al eje o regla de los 180 grados es muy importante. En el sistema de continuidad no importante tanto un "error" o una transgresión concreta de sus normas, como la conjunto del relato y el respeto a la causalidad, lo que lo ha convertido en el sistema dominante a lo largo del tiempo.

4. El sistema de continuidad tiende a eliminar cualquier referencia a lo que se ha denominado "huellas de la instancia enunciadora", es decir, al trabajo de producción, lo que permite la identificación del espectador con los elementos diegéticos.

5. El sistema de continuidad no es un procedimiento narrativo que se haya impuesto por causas naturales, sino por motivos culturales, aunque pueda asemejarse a los modelos de representación dominantes en las épocas de máximo esplendor del sistema de continuidad. De hecho otros sistemas han ido surgiendo en distintas épocas. Hay que destacar la posibilidad de que surjan modelos narrativos audiovisuales donde predomine la causalidad pero no el sistema de montaje basado en el racord o viceversa.

\section{Referencias bibliográficas}

AMIEL, V. (2005). Estética del montaje. Madrid: Abada editores. AUMONT, J. (1997): El ojo interminable. Barcelona: Paidós.

BORDWELL y THOMSON (1993). El arte cinematográfico. Una introducción. Barcelona: Paidós.

BORDWELL, STAIGER y THOMPSON (1997). El cine clásico de Hollywood. Barcelona: Paidós.

BURCH, N. (1987). El tragaluz del infinito. Madrid: Cátedra.

CHION (1993). La audiovisión. Introducción a un análisis conjunto de la imagen y el sonido. Barcelona: Paidós. 
GÓMEZ TARÍN (2011). Elementos de narrativa audiovisual. Expresión y narración. Santander: Shangrila ediciones.

KATZ, S. (2002). Plano a plano. De la idea a la pantalla. Madrid: Plot Ediciones.

ORTEGA Y GASSET (1976). La deshumanización del arte y otros ensayos de estética. Madrid: El arquero.

PINEL, V. (2004). El montaje. El espacio y el tiempo del film. Barcelona: Paidós.

REISZ, K. (1960): Técnica del montaje cinematográfico. Madrid: Editorial Taurus.

SÁNCHEZ, R. (1971): Montaje cinematográfico. Arte del movimiento. Barcelona: Pomaire.

TALENS, J. (1978): El ojo tachado. Lectura de “Un chien andalou” de Luis Buñuel. Madrid: Cátedra.

\section{Notas}

1 BORDWELL, STAIGER y THOMPSON (1997). El cine clásico de Hollywood. Barcelona: Paidós, p. 236

2 PINEL, V. (2004). El montaje. El espacio y el tiempo del film. Barcelona: Paidós, p. 52

3 AUMONT, J. (1997): El ojo interminable. Barcelona: Paidós, p. 74

4 REISZ, K. (1960): Técnica del montaje cinematográfico. Madrid: Editorial Taurus, p. 194

5 CHION (1993). La audiovisión. Introducción a un análisis conjunto de la imagen y el sonido. Barcelona: Paidós, p.17

6 BORDWELL y THOMSON (1993). El arte cinematográfico. Una introducción. Barcelona: Paidós, p. 264

\section{El autor}

Josep Prósper es doctor en Ciencias de la Información por la Universidad Complutense de Madrid y profesor titular de la Universidad Politécnica de Valencia. Su campo de investigación es la narrativa audiovisual y el montaje. Entre sus últimas publicaciones hay que destacar los libros Narrativa Audiovisual. Estrategias y recursos, escrito junto a Fernando Canet, y Elementos constitutivos del relato cinematográfico. Ha publicado, entre otros artículos científicos, Frecuencia y punto de vista: procedimientos para estructurar el relato en la revista Icono 14, Aplicación de la música para estructurar el montaje: fundidos y cadencias musicales en Desayuno con diamantes, en colaboración con Blas Payri, en SituArte, y La imagen subjetiva en Área abierta. 